\title{
KEBERHASILAN PENERAPAN BUDIDAYA PADI RAMAH LINGKUNGAN PADA PROGRAM GERBANG PANGAN SERASI DI KABUPATEN TABANAN
}

\author{
The Success Of The Application Of Eco-Friendly Paddy Cultivation In The \\ GPS (Gerbang Pangan Serasi) Program In Tabanan Regency
}

\section{Gede Urif Bayu Rahayu*, Nyoman Sutjipta, I Dewa Putu Oka Suardi}

Program Studi Magister Agribisnis, Fakultas Pertanian, Universitas Udayana, Bali, Indonesia

*Email : gedebayuurif94@gmail.com

\begin{abstract}
The level of food needs in agriculture sector is increasing. The condition urged the change on agriculture system. Therefore, anagriculture system that is more modern and more eco-friendly should be developed. The purpose of this study was to analyze the influence of the instructor competence on farmers' behavior, the influence of innovation on farmers' behavior, and the influence of the farmers' behavior on the GPS program success. The study took place in Subak Timpag, Subak Koto Bongan, Subak Demung, and Subak Sungi I, which werepurposively selected. The research population was the members of the four subaks that apply eco-friendly paddy cultivation. The samples gathering in each of the subakwas done with Accidental Sampling technique with the total amount of 58 farmers. This study used Partial Least Square analysis. The study results showed that the instructor competence affected in actual way on the farmers' behavior in the application of eco-friendly paddy cultivation; innovation affected in actual way on the farmers' behavior in applying the eco-friendly paddy cultivation; and the farmers' behavior affected in actual way on the success of the application of eco-friendly paddy cultivation.
\end{abstract}

Keywords: the instructor competence, innovation, farmers' behavior

\begin{abstract}
ABSTRAK
Tingkat kebutuhan pangan di sektor pertanian semakin meningkat. Kondisi tersebut menuntut adanya suatu perubahan pada sistem pertanian, maka mulai dikembangkan suatu sistem pertanian yang lebih modern dan lebih ramah lingkungan. Tujuan penelitian ini adalah Menganalisis pengaruh kompetensi penyuluh terhadap perilaku petani, pengaruh sifat inovasi terhadap perilaku petani, dan pengaruh perilaku petani terhadap keberhasilan Program GPS. Lokasi penelitian dilakukan di Subak Timpag, Subak Koto Bongan, Subak Demung, dan Subak Sungi I, yang ditentukan secara seangaja (purposive) Populasi dalam penelitian yaitu anggota petani dari empat Subak yang menerapkan budidaya padi ramah lingkungan. Pengambilan setiap sampel di masing-masing subak dilakukan dengan teknik Accidental Sampling. jumlah sampel yang diambil sebanyak 58 orang petani. Penelitian ini menggunakan analisis Partial Least Squares (PLS). Hasil penelitian menunjukkan pada variabel kompetensi penyuluh berpengaruh nyata terhadap perilaku petani dalam penerapan budidaya padi ramah lingkungan. Sifat inovasi berpengaruh nyata terhadap perilaku petani dalam penerapan budidaya padi ramah lingkungan. Perilaku petani berpengaruh nyata terhadap keberhasilan penerapan budidaya padi ramah lingkungan.
\end{abstract}

Kata Kunci : Program GPS, Penerapan Padi Ramah Lingkungan, Kompetensi Penyuluh, Sifat Inovasi, Perilaku Petani, dan Keberhasilan Program. 


\section{PENDAHULUAN}

\section{Latar Belakang}

Sektor pertanian memiliki peranan yang penting dalam menunjang keberhasilan pembangunan di Indonesia, mengingat sebagian besar penduduk menggantungkan hidupnya dengan bekerja pada sektor pertanian. Tingkat kebutuhan pangan di sektor pertanian semakin meningkat sejalan dengan laju pertumbuhan jumlah penduduk. Kondisi tersebut menuntut adanya suatu perubahan pada sistem pertanian, maka mulai dikembangkan suatu sistem pertanian yang lebih modern dan lebih ramah lingkungan yaitu sistem pertanian organik. Pemerintah Kabupaten Tabanan terus berupaya meningkatkan produksi dan produktivitasnya serta mempertahankan eksistensi sektor pertanian dengan membentuk program usahatani yang mengarah ke sistem pertanian ramah lingkungan. Program unggulan tersebut adalah program Gerakan Pembangunan Pangan, selanjutnya dikenal dengan Gerbang Pangan Serasi (GPS). Program GPS merupakan program yang mengusung usahatani ramah lingkungan menuju usahatani organik atau dapat dikatakan sebuah percontohan sistem pertanian organic. Upaya meningkatkan keberhasilan penerapan budidaya padi ramah lingkungan, salah satunya, Peran Pemda Kabupaten Tabanan yaitu selalu mendampingi dan memberikan penyuluhan terhadap petani mengenai program GPS yang nantinya diharapkan petani memahami dan mempunyai inovasi pada penerapan budidaya padi ramah lingkungan, serta mampu mengubah dan mempertahankan sistem pertanian yang mulanya menggunakan sistem pemupukan dari pupuk kimia menjadi pupuk organik, sehingga dapat meningkatnya kemampuan petani dalam bertani organik dan mencapai keberhasilan yang maksimal dalam penerapan budidaya padi ramah lingkungan, ini akan bermanfaat terhadap peningkatan pendapatan petani dan peningkatan produksi yang didapat oleh petani, sehingga dapat meningkatkan kesejahteraan petani.

\section{Rumusan Masalah}

Dari uraian latar belakang diatas, rumusan masalah yang didapatkan adalah sebagai berikut.

1. Bagaimanakah pengaruh kompetensi penyuluh terhadap perilaku petani dalam penerapan budidaya padi ramah lingkungan di Kabupaten Tabanan?

2. Bagaimanakah pengaruh sifat inovasi terhadap perilaku petani dalam penerapan budidaya padi ramah lingkungan di Kabupaten Tabanan?

3. Bagaimanakah pengaruh perilaku petani terhadap keberhasilan Program Gerbang Pangan Serasi dalam penerapan budidaya padi ramah lingkungan di Kabupaten Tabanan?

\section{Tujuan Penelitian}

Tujuan penelitian secara umum adalah untuk mengetahui Keberhasilan Program Gerbang Pangan Serasi (GPS) pada kelompok tani padi di Kabupaten Tabanan. Secara khusus yang menjadi tujuan penelitian, yaitu :

1. Mengetahui pengaruh kompetensi penyuluh terhadap perilaku petani dalam penerapan budidaya padi ramah lingkungan di Kabupaten Tabanan.

2. Mengetahui pengaruh sifat inovasi terhadap perilaku petani dalam penerapan budidaya padi ramah lingkungan di Kabupaten Tabanan.

3. Mengetahui pengaruh perilaku petani terhadap keberhasilan Program Gerbang Pangan Serasi dalam penerapan budidaya padi ramah lingkungandi Kabupaten Tabanan.

\section{METODE PENELITIAN}

\section{Lokasi dan Waktu Penelitian}

Penelitian ini dilakukan di Subak Timpag, Kec Kerambitan, Subak Koto Bongan, Kec Tabanan, Subak Demung, Kec Kediri, dan Subak Sungi I, Kec Marga. Pemilihan 4 (empat) Subak dilakukan berdasarkan metode Purposive Sampling yang mana setiap subak dipilih secara sengaja sesuai dengan kebutuhan peneliti. Sedangkan waktu penelitian direncanakan akan dilakukan pada bulan November sampai dengan Januari 2019.

\section{Populasi dan Sampel}

Populasi dalam penelitian ini adalah anggota petani dari 4 (empat) Subak yang menerapkan budidaya padi ramah lingkungan pada Program GPS di Kabupaten Tabanan, dengan jumlah seluruhnya 136 orang. Teknik sampling dalam penelitian ini dilakukan dengan menerapkan metode propotional purposive sampling. Dimana diperoleh jumlah sampel minimal 58 orang petani yang menerapkan budidaya padi ramah lingkungan program GPS. Pengambilan setiap sampel di masing-masing subak dilakukan dengan teknik Accidental Sampling. Menurut sugiyono (2009), Accidental Sampling adalah teknik penentuan sampel berdasarkan kebetulan, yaitu petani yang secara kebetulan/insidental bertemu dengan peneliti dapat digunakan sebagai sampel, karena sampel penelitian yang cenderung bersifat homogen dan mengetahui kegiatan budidaya padi ramah lingkungan pada Program Gerbang Pangan Serasi, sehingga dianggap mampu mewakili seluruh populasi yang ada, ketepatan dan kepercayaan bahwa sampel yang diambil telah dapat mengukur parameter yang diduga dalam 
penelitian ini, keterbatasan waktu, biaya, dan sumber daya lainnya yang dimiliki oleh peneliti.

\section{Variabel Penelitian}

Variabel-variabel yang digunakan dalam penelitian ini, meliputi (i) karakteristik konsumen dengan indicator Luas garapan, umur petani, lama pendidikan formal, jumlah tangguang keluarga, lama pengalaman usahatani, (ii) Kompetensi penyuluh di Kabupaten Tabanan dengan indicator keterampilan berkomunikasi, penguasaan materi, kemampuan memotivasi, dan interaksi social. (iii) Sifat inovasi dengan indicator keuntungan relatif, kesesuaian inovasi, tingkat kerumitan, dapat dicoba, dan mudah diamati. (iv) Perilaku petani dengan indikator pengetahuan, sikap, dan penerapan. (v) Keberhasilan program dengan indikator perluasan area tanam, peningkatan indeks penanaman, peningkatan produksi dan peningkatan pendapatan.

\section{Metode Analisis Data}

Semua indikator dan parameter dari variabel penelitian diukur dengan skor, yaitu dari skor 1 s.d. 5. Setelah memperoleh data, maka data dianalisis dengan alat analisis sebagai berikut.

\section{Partial Least Squares (PLS)}

$P L S$ digunakan untuk tujuan penelitian kedua dan ketiga. Adapun kriteria-kriteria yang harus dipenuhi untuk analisis ini adalah sebagai berikut.

\section{Evaluasi pengukuran (outer model)}

Outer model digunakan untuk menilai validitas dan reabilitas model. Outer model dengan indikator refleksif dievaluasi melalui convergent validity dan discriminant validity dari indikator pembentuk konstruk laten, sedangkan composite reability untuk mengukur reabilitas suatu konstruk dengan indikator refleksif (Chin, 1998 dalam Gozali, 2015). Secara lebih rinci dapat dijelaskan sebagai berikut.

\section{Convergent Validity}

Convergent Validity berhubungan dengan prinsip bahwa pengukuran-pengukuran (manifest variabel) dari suatu indikator konstruk seharusnya berkolerasi tinggi. Pengujian convergent validity indikator refleksif dengan program SmartPLS 3.0 dapat dilihat dari nilai loading factor untuk tiap indikator konstruk. Nilai loading factor harus lebih dari 0,7 . untuk penelitian yang bersifat confirmatory dan nilai loading faktor antara 0,6 s.d. 0,7. Namun demikian untuk penelitian tahap awal dari pengembangan skala pengukuran nilai loading factor 0,5 s.d. 0,6 masih dianggap cukup (Chin, 1998 dalam Gozali, 2015).

2. Discriminant Validity
Discriminant Validity berhubungan dengan prinsip bahwa pengukuran-pengukuran konstruk (manifest variable) yang berbeda seharusnya tidak berkolerasi tingggi. Nilai ini merupakan nilai cross loadings yang berguna untuk mengetahui apakah konstruk memiliki diskriminasi yang memadai. Cara untuk menguji discriminant validity yaitu membandingkan nilai cross loading yang dituju harus lebih besar dibandingkan dengan nilai cross loading dengan konstruk yang lain (Mustafa dan Wijaya, 2012).

3. Composite Reliability

Uji reliabilitas suatu konstruk dengan indikator refleksif Ini dilakukan untuk membuktikan akurasi, konsistensi dan ketetapan instrumen dalam mengukur konstruk. Uji ini dapat dilakukan dengan melihat nilai composite reliability. Nilai yang diharapkan harus lebih besar dari 0,6 (Mustafa dan Wijaya, 2012).

\section{Evaluasi model struktural (inner model)}

Evaluasi inner model dapat dilakukan dengan tiga cara. Ketiga cara tersebut adalah dengan struktural $P L S$ dapat dilihat dari nilai $R$-Squares untuk setiap variabel laten sebagai kekuatan prediksi dari model struktural. Perubahan nilai $R$-Squares digunakan untuk menjelaskan pengaruh variabel laten eksogen tertentu terhadap variabel laten endogen, apakah mempunyai pengaruh substantive. Nilai $R$-Squares 0,$67 ; 0,33$ dan 0,19 untuk variabel laten endogen dalam model struktural menunjukkan model kuat, moderat, dan lemah (Chin, 1998 dalam Ghozali, 2012).

Berikut untuk pengujian Inner model dapat dilakukan dengan melihat nilai $\mathrm{Q}^{2}$ (predictive relevance). Untuk menghitung $\mathrm{Q}^{2}$ dapat digunakan rumus:

$$
\mathrm{Q}^{2}=1-\left(1-\mathrm{R}_{1}^{2}\right)\left(1-\mathrm{R}_{2}^{2}\right) \ldots\left(1-\mathrm{R}_{\mathrm{p}}^{2}\right)
$$

Yang terakhir adalah dengan mencari nilai Goodness of Fit (GoF). Nilai GoF pada PLS harus dicari secara manual dengan rumus berikut.

$$
\begin{aligned}
\mathrm{GoF} & =\sqrt{\overline{\text { Communality } \times \bar{R}^{2}}} \\
& =\sqrt{\overline{A V E \times \bar{R}^{2}}}
\end{aligned}
$$

Menurut Tenenhau (2004) dalam Hussein (2015), nilai GoF small $=0,1, \mathrm{GoF}$ medium $=0,25$ dan $\mathrm{GoF}$ big $=0,38$.

\section{Pengujian Hipotesis}

Hasil ini dapat dilihat pada path coeficients. Pengujian hipotesis dilakukan dengan uji statistik $\mathrm{t}(t$-test). Kalau dalam pengujian ini diperoleh $p$ value $<0,01 ; 0,05$; (alpha 1\%; 5\%) atau t statistik $>\mathrm{t}$ tabel, berarti pengujian signifikan, dan sebaliknya kalau $p$-value $>0,01,0,05$; (alpha 1\%; $5 \%$ ) atau $\mathrm{t}$ statistik $<\mathrm{t}$ tabel, berarti tidak signifikan. Bilamana hasil pengujian hipotesis 
pada outer model signifikan, hal ini menunjukkan bahwa indikator dipandang dapat digunakan sebagai instrumen pengukur variabel laten. Sementara, bilamana hasil pengujian pada inner model adalah signifikan, maka dapat diartikan bahwa terdapat pengaruh yang bermakna variabel laten satu terhadap variabel laten lainnya. (Chin, 1998; Hair et al ,2011; Henseler et al, 2009, dalam Gozali, 2015).

\section{HASIL DAN PEMBAHASAN}

\section{Karakteristik Konsumen}

Dalam penelitian ini karakteristik konsumen diidentifikasi berdasarkan berdasarkan umur, luas garapan, lama pendidikan formal, jumlah tanggungan keluarga, dan lama pengalaman berusahatani. Karakteristik luas garapan petani padi ramah lingkungan di Kabupaten Tabanan yang berpartisipasi dalam Program GPS (Gerbang Pangan Serasi) menunjukkan bahwa sebanyak 22 orang atau sebesar $38,10 \%$ dari total sampel petani padi ramah lingkungan di Kabupaten Tabanan menggarap lahan seluas $\leq 0,25$ hektar, sedangkan sebanyak dua orang atau sebesar 3,01 $\%$ dari total sampel petani padi ramah lingkungan di Kabupaten Tabanan menggarap lahan seluas > 1,00 hektar. Karakteristik umur petani padi ramah lingkungan di Kabupaten Tabanan yang berpartisipasi dalam Program GPS menunjukkan sebanyak 15 orang atau sebesar $25,86 \%$ dari total sampel petani padi ramah lingkungan di Kabupaten Tabanan berumur lebih dari 55 sampai dengan 65 tahun, sedangkan sebanyak empat orang atau sebesar $6,90 \%$ dari total sampel petani padi ramah lingkungan di Kabupaten Tabanan berumur $\leq 35$ tahun. Umur petani padi ramah lingkungan di Kabupaten Tabanan akan mempengaruhi proses penerapan inovasi Program GPS. Karakteristik lama pendidikan formal petani padi ramah lingkungan di Kabupaten Tabanan yang berpartisipasi dalam Program GPS menunjukkan bahwa sebanyak 9 orang atau sebesar $15,52 \%$ dari total sampel petani padi ramah lingkungan di Kabupaten Tabanan menempuh pendidikan formal selama $\leq$ enam tahun, sedangkan sebanyak lima orang atau sebesar 8,62 \% dari total sampel petani padi ramah lingkungan di Kabupaten Tabanan menempuh pendidikan formal selama lebih dari 12 tahun sampai dengan 15 tahun. Karakteristik jumlah tanggungan keluarga petani padi ramah lingkungan di Kabupaten Tabanan yang berpartisipasi dalam Program GPS menunjukkan bahwa sebanyak 33 orang atau sebesar 56,90\% dari total sampel petani padi ramah lingkungan di Kabupaten Tabanan memiliki jumlah tanggungan keluarga sebanyak tiga sampai dengan empat orang, sedangkan sebanyak sembilan orang atau sebesar $15,52 \%$ dari total sampel petani padi ramah lingkungan di Kabupaten Tabanan memiliki jumlah tanggungan keluarga sebanyak lebih dari empat orang Karakteristik lama pengalaman usahatani petani padi ramah lingkungan di Kabupaten Tabanan yang berpartisipasi dalam Program GPS pada Tabel 6.5 menunjukkan bahwa sebanyak 12 orang atau sebesar 20,69\% dari total sampel petani padi ramah lingkungan di Kabupaten Tabanan memiliki lama pengalaman usahatani selama lebih dari 40 tahun, sedangkan sebanyak tiga orang atau sebesar 5,17\% dari total sampel petani padi ramah lingkungan di Kabupaten Tabanan memiliki lama pengalaman usahatani selama kurang dari 11 tahun dengan jumlah petani.

Deskripsi Faktor-Faktor yang Mempengaruhi Keberhasilan Penerapan Budidaya Padi Ramah Lingkungan Pada Program GPS di Kabupaten Tabanan

Kompetensi penyuluh terdiri dari empat indikator yang meliputi: indikator keterampilan berkomunikasi, penguasaan materi, kemampuan memotivasi, dan kemampuan interaksi sosial. Nilai capaian skor kompetensi penyuluh sebesar 4.132 yang berarti penyuluh di Kabupaten Tabanan sudah berkompeten dalam melakukan penyuluhan dan membina petani padi yang berpartisipasi dalam penerapan budidaya padi ramah lingkungan pada program GPS. Sifat inovasi terdiri dari lima indikator yang meliputi: keuntungan relatif, kesesuaian inovasi, tingkat kerumitan, dapat dicoba, dan mudah dipahami. Nilai capaian skor sifat inovasi sebesar 1.157 yang berarti sifat inovasi yang ditawarkan kepada petani di Kabupaten Tabanan dalam penerapan budidaya padi ramah lingkungan pada program GPS sudah baik. Perilaku petani terdiri dari tiga indikator yang meliputi: pengetahuan, sikap, dan keterampilan. Nilai capaian skor perilaku petani sebesar 17.020 yang berarti perilaku petani padi di Kabupaten Tabanan yang berpartisipasi dalam penerapan budidaya padi ramah lingkungan pada program GPS sudah Sesuai. Keberhasilan penerapan budidaya padi ramah lingkungan pada program GPS terdiri dari empat indikator yang meliputi: peningkatan indeks penanaman, perluasan areal tanam, peningkatan produksi, dan peningkatan pendapatan. Nilai capaian skor keberhasilan program penerapan budidaya padi ramah lingkungan pada program GPS sebesar 965 yang berarti pelaksanaan keberhasilan penerapan budidaya padi ramah lingkungan pada program GPS di Kabupaten Tabanan sudah cukup berhasil.

Pengaruh $\begin{aligned} & \text { Faktor-Faktor } \\ & \text { Keberhasilan } \\ & \text { Penerapan }\end{aligned}$ Budidaya Padi
Ramah Lingkungan Pada Program GPS di
Kabupaten Tabanan

Evaluasi model pengukuran (outer model) 
Ghozali (2011), mengemukakan bahwa evaluasi model pengukuran (outer model) dievaluasi dengan convergent validity, discriminant validity dari indikatornya, dan composite reliability untuk blok indikator.

1. Convergent validity

Kontribusi setiap indikator membentuk variabel konstruk dapat dilihat dari nilai outer loading.
Semakin besar nilai outer loading maka semakin kuat indikator membentuk konstruk. Ukuran refleksif individual dikatakan tinggi jika berkorelasi lebih dari 0,70 dengan konstruk yang ingin diukur, namun demikian untuk penelitian tahap awal dari pengembangan skala pengukuran nilai loading 0,5 sampai 0,6 dianggap cukup (Chin 1998, dalam Ghozali 2011).

Tabel 1. Hasil Pengujian Outer Model

\begin{tabular}{clc}
\hline Konstruk & \multicolumn{1}{c}{ Indikator } & Outer Loading \\
\hline \multirow{3}{*}{ Kompetensi penyuluh } & Keterampilan berkomunikasi & 0,817 \\
& Penguasaaan materi & 0,722 \\
& Kemampuan memotivasi & 0,715 \\
& Interaksi social & 0,682 \\
\hline \multirow{2}{*}{ Sifat inovasi } & Keuntungan relative & 0,742 \\
& Kesesuaian inovasi & 0,723 \\
& Tingkat kerumitan & 0,552 \\
& Dapat dicoba & 0,574 \\
& Mudah diamati & 0,689 \\
\hline \multirow{2}{*}{ Perilaku petani } & Pengetahuan & 0,808 \\
& Sikap & 0,606 \\
& Penerapan & 0,833 \\
\hline \multirow{2}{*}{ Keberhasilan Program GPS } & Peningkatan Indeks Penanaman & 0,561 \\
(Gerbang Pangan Serasi) & Perluasan Area Tanam & 0,589 \\
& Peningkatan Produksi & 0,747 \\
& Peningkatan Pendapatan & 0,598 \\
\hline
\end{tabular}

Hasil pengujian outer model pada Tabel 3.1 menunjukkan bahwa masing-masing indikator yang mengukur konstruk kompetensi penyuluh, sifat inovasi, perilaku petani, dan keberhasilan Program GPS (Gerbang Pangan Serasi) memiliki nilai outer loading lebih besar dari 0,5. Hal ini menunjukkan bahwa seluruh indikator penelitian tahap awal dari pengembangan sudah dinyatakan cukup valid untuk mengukur konstruk (Chin 1998, dalam Ghozali, 2011)

\section{Discriminant Validity}

Tabel 2. Hasil Pengujian Discriminant Validity

\begin{tabular}{ccccc}
\hline & Kompetensi penyuluh & Perilaku Petani & Keberhasilan Program & Sifat Inovasi \\
\hline KB1 & 0,234 & 0,377 & 0,561 & 0,163 \\
KB2 & 0,134 & 0,45 & 0,598 & 0,268 \\
KB3 & 0,371 & 0,586 & 0,747 & 0,264 \\
KB4 & 0,319 & 0,446 & 0,598 & 0,191 \\
KP1 & 0,817 & 0,470 & 0,303 & 0,285 \\
KP2 & 0,722 & 0,453 & 0,413 & 0,333 \\
KP3 & 0,715 & 0,337 & 0,295 & 0,227 \\
KP4 & 0,682 & 0,235 & 0,203 & 0,034 \\
PP1 & 0,426 & 0,808 & 0,711 & 0,407 \\
PP2 & 0,379 & 0,606 & 0,298 & 0,379
\end{tabular}




\begin{tabular}{lcccc} 
PP3 & 0,417 & 0,833 & 0,611 & 0,482 \\
SI1 & 0,232 & 0,435 & 0,204 & 0,742 \\
SI2 & 0,257 & 0,433 & 0,349 & 0,723 \\
SI3 & 0,04 & 0,217 & 0,202 & 0,552 \\
SI4 & 0,256 & 0,219 & 0,069 & 0,574 \\
SI5 & 0,265 & 0,429 & 0,282 & 0,689 \\
\hline
\end{tabular}

Hasil pengujian discriminant validity pada Tabel 3.2 menunjukkan bahwa nilai korelasi konstruk kompetensi penyuluh dengan indikatornya (KP1, $\mathrm{KP} 2, \mathrm{KP} 3$ dan KP4) lebih tinggi dari pada korelasi indikator (PP1, PP2, PP3, KB1, KB2, KB3, KB4, SI1, SI2, SI3, SI4, dan SI5) atau dengan variabel kontruk lainnya. Hal ini juga berlaku untuk indikator-indikator yang mencerminkan variabel perilaku petani, keberhasilan program dan sifat inovasi yang tentunya memiliki nilai korelasi lebih tinggi dari pada variabel konstruk lainnya. Dengan demikian indikator-indikator yang dipergunakan dalam penelitian ini adalah valid atau telah memenuhi discriminat validity.

3. Composite reliability

Tabel 3

Hasil Pengujian Composite Reliability

\begin{tabular}{lcc}
\hline \multicolumn{1}{c}{ Variabel Laten } & $\begin{array}{c}\text { Jumlah } \\
\text { Indikator }\end{array}$ & Composite Reliability \\
\hline Kompetensi penyuluh & 4 & 0,824 \\
Sifat inovasi & 5 & 0,793 \\
Perilaku petani & 3 & 0,797 \\
Keberhasilan Program GPS (Gerbang Pangan Serasi) & 4 & 0,722 \\
\hline
\end{tabular}

Hasil pengujian composite reliability pada Tabel 3.3 menunjukkan bahwa konstruk kompetensi penyuluh, sifat inovasi, perilaku petani, dan keberhasilan Program GPS (Gerbang Pangan

\section{Evaluasi model struktural (inner model)}

Nilai-nilai koefisien jalur dari hubungan antarlaten pada model persamaan struktural yang dibangun diperlihatkan pada Gambar 1.

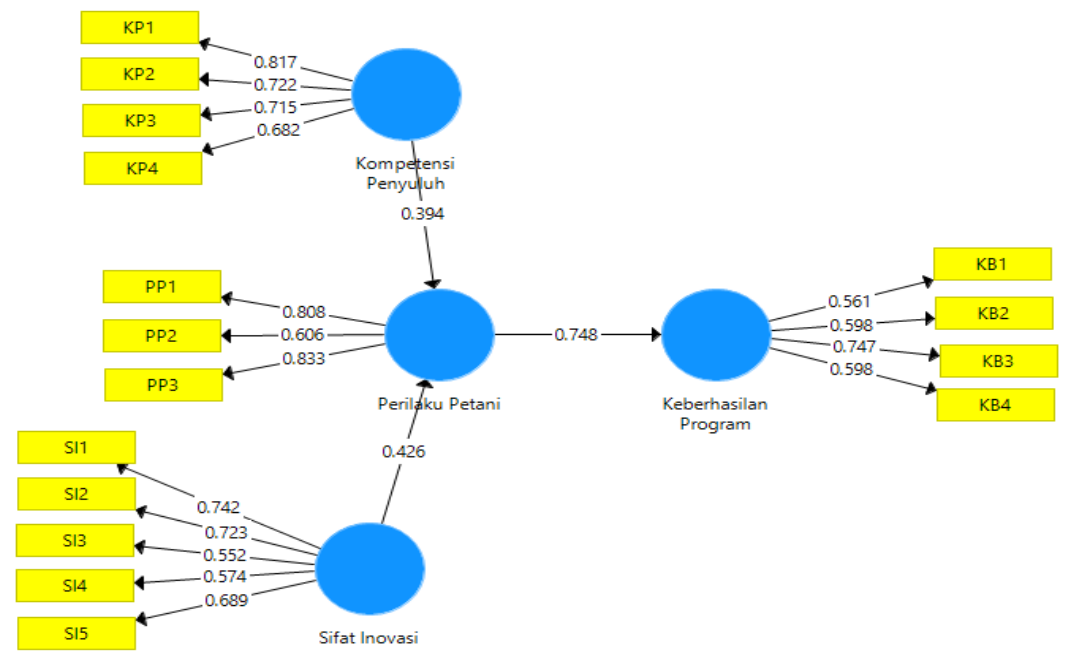

Gambar 1. Model Struktural Variabel-Variabel yang Mempengaruhi Perilaku Petani dan Keberhasilan Program 
Nilai-nilai ini menunjukkan pengaruh-pengaruh langsung (direct effects) dari setiap laten eksogenus terhadap laten endogenus yang bersesuaian. Selain pengaruh langsung, dalam model persamaan struktural yang melibatkan hubungan antarlaten, juga bisa diperiksa pengaruh-pengaruh tak langsung (indirect effects) dari laten eksogenus terhadap laten endogenus melalui mediasi laten yang lain. Hasil pada gambar 1 menunjukan bahwa kompetensi penyuluh yang terdiri dari keterampilan berkomunikasi, pengusaan materi, kemampuan memotivasi, interasi sosial dan sifat inovasi yang terdiri dari keuntungan relatif, tingkat kesesuaian, tingkat kerumitan, dapat dicoba dan mudah diamati yang merupakan variabel eksogenus berpengaruh positif/langsung pada perilaku petani, dan perilaku petani yang terdiri dari sikap, pengetahuan dan keterampilan yang merupakan variabel eksogenus/endogenus berpengaruh positif/langsung terhadap keberhasilan penerapan budidaya padi ramah lingkungan pada program GPS yang merupakan variabel endogenus.

Tabel 4. Uji Model Struktural

\begin{tabular}{|c|c|c|c|c|c|}
\hline Variabel Laten & Jenis Variabel & $\begin{array}{l}\text { Jumlah } \\
\text { Indikator }\end{array}$ & $\begin{array}{c}\text { Composite } \\
\text { Reliability (CR) }\end{array}$ & $\begin{array}{l}\text { Average Variance } \\
\text { Extracted (AVE) }\end{array}$ & $\mathrm{R}^{2}$ \\
\hline $\begin{array}{l}\text { Kompetensi } \\
\text { Penyuluh }\end{array}$ & Eksogenus & 4 & 0,824 & 0,541 & $\mathrm{NA}^{\mathrm{a}}$ \\
\hline Sifat Inovasi & Eksogenus & 5 & 0,793 & 0,437 & $\mathrm{NA}^{\mathrm{a}}$ \\
\hline Perilaku Petani & Eksogenus/Endogenus & 3 & 0,797 & 0,571 & 0,448 \\
\hline $\begin{array}{l}\text { Keberhasilan } \\
\text { Program }\end{array}$ & Endogenus & 4 & 0,722 & 0,397 & 0,560 \\
\hline Rata-Rata & & & & 0,478 & 0,504 \\
\hline
\end{tabular}

Berikut untuk pengujian Inner model dapat dilakukan dengan melihat nilai Q2 (predictive relevance). Untuk menghitung Q2 dapat digunakan rumus:

$$
\begin{array}{ll}
Q \text {-square } & =1-\left(1-\mathrm{R}^{2} \mathrm{PP}\right) \times\left(1-\mathrm{R}^{2} \mathrm{KPU}\right) \\
Q \text {-square } & =1-(1-0,448) \times(1-0,560) \\
Q \text {-square } & =0,757
\end{array}
$$

Hasil pengujian $Q$-square diatas menunjukkan bahwa konstruk perilaku petani dan keberhasilan program GPS memiliki nilai $Q$-square sebesar 0,757 , yang artinya model memiliki nilai predictive relevance. Hal ini mengindikasikan bahwa model dan estimasi parameternya memiliki nilai observasi yang baik.

Selanjutnya untuk menilai kelayakan model persamaan struktural secara utuh, maka nilai Goodness of Fit ( $\mathrm{GoF}$ ) dari model bisa dilakukan dengan merujuk formula yang diperkenalkan oleh Tenenhaus et al. (2005) sebagai berikut.

$\mathrm{GoF}=\sqrt{\overline{\text { Coummunality } \times R^{2}}}=$ $\sqrt{\overline{A V E X R^{2}}}$

$$
=\sqrt{0,478 \times 0,504}=\underline{\underline{\underline{\underline{0}}}}, 491
$$

Pada persamaan di atas, AVE merupakan nilai rataan terbobot dengan bobot diperoleh dari jumlah indikator untuk setiap variabel laten. Menggunakan formula ini, diperoleh nilai GoF dari model sebesar 0,491, yang artinya sebuah ukuran yang melebihi nilai ambang GoF bernilai big, Menurut Tenenhau (2004) dalam Hussein (2015), nilai GoF small $=0,1$, GoF medium $=0,25$ dan GoF big $=0,38$, untuk menyatakan model bisa

\begin{tabular}{|c|c|c|c|c|c|}
\hline Var. Eksogenus & & Var. Endogenus & Koefisien & Standar Deviasi & T-Statistik \\
\hline Kom. Penyuluh & $\Rightarrow$ & Perilaku Petani & 0,119 & 0,085 & $4,618 *$ \\
\hline Perilaku Petani & $\Rightarrow$ & Keberhasilan Program & 0,389 & 0,096 & $18,886^{*}$ \\
\hline Sifat Inovasi & $\Rightarrow$ & Perilaku Petani & 0,357 & 0,082 & $4,660^{*}$ \\
\hline
\end{tabular}
diterima dan interpretasi analisis bisa dilanjutkan.

\section{Pengaruh Variabel Eksogenus terhadap Variabel Endogenus}

Tabel 5. Pengaruh Variabel Eksogenus terhadap Variabel Endogenus

Keterangan :

ns : tidak signifikan

* : signifikan pada taraf uji $1 \%$

Pengaruh variabel eksogenus terhadap variabel endgenus dapat dijelaskan secara rinci sebagai berikut.
Pengaruh Kompetensi Penyuluh Terhadap Perilaku Petani 
Konstruk kompetensi penyuluh berpengaruh nyata pada taraf signifikansi $1 \%(\alpha=0,01)$ terhadap konstruk perilaku petani dengan nilai $p$-value sebesar 0,000 dan nilai $t$ hitung $(4,618)>t$ tabel sebesar 2,66. Hal ini menunjukkan bahwa kompetensi penyuluh di Kabupaten Tabanan berpengaruh nyata dalam meningkatkan pengetahuan, merubah sikap, dan dapat memperbaiki cara-cara berusahatani atau keterampilan petani padi yang menerapkan budidaya padi ramah lingkungan pada program GPS.

\section{Pengaruh Sifat Inovasi Terhadap Perilaku Petani}

Konstruk sifat inovasi berpengaruh nyata pada taraf signifikansi $1 \%(\alpha=0,01)$ terhadap konstruk perilaku petani dengan nilai $p$-value sebesar 0,000 dan nilai t hitung $(4,660)>t$ tabel sebesar 2,66. Hal ini menunjukkan bahwa sifat inovasi di Kabupaten Tabanan berpengaruh nyata dalam meningkatkan pengetahuan, merubah sikap, dan dapat meningkatkan keterampilan petani mengadopsi inovasi dalam penerapan budidaya padi ramah lingkungan pada program GPS.

\section{Pengaruh Perilaku Petani Terhadap Kebarhasilan Program}

Konstruk perilaku petani berpengaruh nyata pada taraf signifikansi $1 \%(\alpha=0,01)$ terhadap konstruk perilaku petani dengan nilai $p$-value sebesar 0,000 dan nilai t hitung $(18,886)>t$ tabel sebesar 2,66. Hal ini menunjukkan bahwa perilaku petani padi di Kabupaten Tabanan berpengaruh nyata terhadap keberhasilan penerapan budidaya padi ramah lingkungan pada program GPS. Petani yang berperan sebagai pelaku usahatani mempengaruhi penerapan budidaya padi ramah lingkungan pada program GPS di kabupaten Tabanan.

\section{KESIMPULAN DAN SARAN}

\section{Kesimpulan}

Berdasarkan hasil analisis dan pembahasan yang telah dilakukan dalam penelitian ini, maka dapat diperoleh simpulan sebagai berikut. Kompetensi penyuluh berpengaruh nyata terhadap perilaku petani dalam penerapan budidaya padi ramah lingkungan di Kabupaten Tabanan. Kompetensi penyuluh yang mempengaruhi perilaku petani tersebut meliputi keterampilan berkomunikasi, penguasaan materi, kemampuan memotivasi, dan interaksi social kompetensi penyuluh dengan petani. Sifat inovasi berpengaruh nyata terhadap perilaku petani dalam penerapan budidaya padi ramah lingkungan di Kabupaten Tabanan. Sifat inovasi yang mempengaruhi perilaku petani tersebut meliputi keuntungan relatif, kesesuaian inovasi, tingkat kerumitan, dapat dicoba, dan mudah diamati. Perilaku petani berpengaruh nyata terhadap keberhasilan penerapan budidaya padi ramah lingkungan pada program GPS (gerbang pangan serasi) di kabupaten Tabanan. Perilaku petani yang mempengaruhi keberhasilan penerapan budidaya padi ramah lingkungan pada program GPS meliputi Pengetahuan Sikap dan Ketrampilan.

\section{Saran}

Berdasarkan hasil analisis dan pembahasan yang telah dilakukan dalam penelitian ini, maka dapat diberikan beberapa saran sebagai berikut. Kompetensi penyuluh di Kabupaten Tabanan dalam menguasai materi untuk mengidentifikasi masalah-masalah baru perlu ditingkatkan agar petani padi yang berpartisipasi dalam penerapan budidaya padi ramah lingkungan pada program GPS (gerbang pangan serasi) lebih cepat menemukan solusi untuk bertindak. Kesesuaian inovasi penerapan budidaya padi ramah lingkungan pada program GPS (gerbang pangan serasi) perlu ditingkatkan agar inovasi yang ditawarkan sesuai dengan kondisi dan kebutuhan petani padi di Kabupaten Tabanan. Pendidikan informal berupa pelatihan maupun bimbingan teknis kepada petani perlu ditingkatkan melalui kursus-kursus singkat yang diselenggarakan secara rutin agar petani padi di Kabupaten Tabanan yang mayoritas mengikuti jenjang pendidikan formal hingga sekolah dasar mampu mengelola usahataninya dengan baik. Pengembangan penelitian lain perlu dilakukan dengan konstruk dan indikator yang berbeda untuk mendukung pemerintah dalam mengambil kebijakan pada sektor pertanian.

\section{DAFTAR PUSTAKA}

Adnyana, I N.S. 2016. "Peranan Sistem Agribisnis Terhadap Keberhasilan Tumpangsari Cabai-Tembakau Kasus Subak Di Desa Sukawati, Kecamatan Sukawati, Kabupaten Gianyar". Denpasar. Fakultas Pertanian Universitas Udayana.

Andoko, A. 2002. Budidaya Padi Secara Organik. Penebar Swadaya. Depok.

Arikunto. 2006. Prosedur Penelitian Suatu Pendekatan Praktek. Jakarta. PT.Rineka Cipta.

BPS. 2016. Produksi, Luas Panen, dan Produktivitas Padi di Indonesia Tahun 2013-2016. Kementrian Pertanian. Indonesia.

BP3K. 2015. Budidaya padi ramah lingkungan. Kabupaten Tabanan. 
Dinas Pertanian. 2017. Surat Keputusan Nomor 029/DISTAN/2017 Tentang Penetapan Kelompoktani Penerima Bantuan Pemerintah Kegiatan Pengelolaan Produksi Tanaman Serealia Berupa Budidaya Padi Inhibrida Tahun Anggaran 2017. Tabanan. Dinas Pertanian.

Ghozali, Imam. 2006. Aplikasi Analisis Multivariate dengan Program SPSS. Badan Penerbit Universitas Diponegoro. Semarang.

Ghozali, Imam. 2008. Structural Equation Modeling, Metode Alternatif dengan Partial Least Square, Badan Penerbit Universitas Diponegoro. Semarang.

Husein, A.S., 2015. Penelitian Bisnis dan Manajemen Menggunakan Partial Least Squares (PLS) dengan smartPLS 3.0. Universitas Brawijaya, Malang.

Kementan, 1992. UU No 12/1992 Tentang Sistem Budidaya Tanaman. Kementrian Pertanian. Indonesia.

Kementan. 2014. Peraturan Menteri Pertanian Nomor: 01/Permentan/OT.140/1/ 2014 Tentang Pedoman Pengembangan Usaha Agribisnis Perdesaan. Kementrian Pertanian. Indonesia.

Kementan. 2017. Pedoman Pelaksanaan Kegiatan Padi Tahun 2017. Direktorat Jenderal Tanaman Pangan Kementrian Pertanian. Indonesia.

Mustafa dan Wijaya. 2012. Panduan Teknik Statistik SEM \& PLS dengan SPSS AMOS. Yogyakarta. Cahaya Atma Pustaka.

Pebriantari NLA, I Nyoman GU, I Made S. 2016. Analisis Pendapatan Usahatani Padi Sawah pada Program Gerbang Pangan Serasi Kabupaten Tabanan. EJAA.Vol 5 No 1.ISSN : 2301-6523.

Pratiwi, Efrita Riadiani. 2010. Perilaku Petani Dalam Mengelola Lahan Pertanian di Kawasan Rawan Bencana Longsor (Studi Kasus Desa Sumberejo, Kecamatan Batur, Kabupaten Banjarnegara Jawa Tengah). Yogyakarta. Jurnal Bumi Indonesia UGM.
Soekartawi. 1988. Pembangunan Pertanian untuk Pengentasan Kemiskinan. Jakarta : UI Press.

Soekartawi. 1988. Prinsip Dasar Komunikasi Pertanian. Jakarta:UI-Press.

Sugiyono. 2004. Statistika Untuk Penelitian. Bandung : CV. Alfabeta.

Suprihono. B. 2003. Analisis Efisiensi Usaha Tani Padi pada Lahan Sawah di Kecamatan Karanganyar Kabupaten Demak. Tesis, Magister Ilmu Ekonomi Studi Pembangunan, Fakultas Ekonomi, Universitas Diponegoro.

Thoha, Miftah. 2003. Pelaku Organisasi, Konsep Dasar dan Aplikasinya. Jakarta: PT. Raja Grafindo Persada. 